\title{
USABILIDADE E ADEQUAÇÃO DE PEÇA SANITÁRIA DESTINADA A PESSOAS COM MOBILIDADE REDUZIDA E IDOSOS
}

\author{
Ekaterina Emmanuil Inglesis Barcellos (1) \\ Galdenoro Botura Jr (2) \\ Rosana Gonçalves Oliveira Rocha (3) \\ Luis Carlos Paschoarelli (4) \\ Rodrigo Curimbaba (5) \\ Fausto Orsi Medola (6)
}

(1) Universidade Estadual Paulista, Doutoranda e Mestre em Design

ekaterina@faac.unesp.br

(2) Universidade Estadual Paulista, Prof. Dr.

galdenoro@gmail.com

(3) Universidade Estadual Paulista, Doutoranda e Mestre em design

rosana@faac.unesp.br

(4) Universidade Estadual Paulista, Prof. Dr.

paschoarelli@faac.unesp.br

(5) Universidade Estadual Paulista, Mestre em Design

nunescurimbaba@hotmail.com

(6) Universidade Estadual Paulista, Prof. Dr.

faustomedola@faac.unesp.br

\begin{abstract}
RESUMO
Este artigo aborda a adequação e usabilidade de um modelo de peça sanitária destinada a atender indivíduos com restrição de movimentos e idosos. A peça é disponibilizada em locais públicos e comerciais, sendo utilizada em sanitários coletivos, além dos restritos a acessibilidade. O estudo objetivou verificar se o design do produto se adequa aos usuários em geral. A pesquisa verificou e colheu dados junto a usuários diversos, com e sem restrição de movimentos, de jovens e idosos. Os resultados apontam que o produto, tal qual é disponibilizado, acarreta risco, desconforto físico e emocional, constrangimento e falhas de salubridade.
\end{abstract}




\section{ABSTRACT}

This article discusses the suitability and usability of toilet bowl design provided to meet individuals with restricted movement and the elderly. The model is available in public and commercial locations, and is used in collective sanitary, in addition to specific and restricted accessibility needs. The survey found that the design of this product is not suitable for general users. It brings risk, physical and emotional distress, embarrassment and generates health failures. The study performed the verification and collected data from the multiple users, with and without restriction of movement, from young to elderly, attesting evidential results and supports by ABNT.

\section{INTRODUÇÃO}

Peças sanitárias fazem parte do cotidiano e da vida das pessoas, especialmente nas culturas ocidentais. Estão presentes no dia-a-dia de uma forma inevitável, devido ao contexto cultural de sua utilização. Estas peças interferem mais diretamente na usabilidade dos indivíduos que se servem delas com maior constância e frequência. Por esse motivo devem ser avaliadas com cautela, e expostas a testes com uma diversidade de visões e opiniões abrangentes, antes de serem definidas como adequadas para uso público, geral e irrestrito.

As questões que incidem sobre o produto bacia sanitária, em sua utilização no espaço público, incluem função, necessidade, expectativa, proposta de design, usabilidade, conforto e adequação. Estes fatores determinam sua maior ou menor aceitação. A instalação de bacias sanitárias em locais públicos difere das instalações residenciais. No ambiente residencial a escolha parte das preferências pessoais na usabilidade, e atende a anseios específicos de quem habita o imóvel. Quando se aborda o espaço público, não ocorre a mesma coisa. Há a incidência de diferentes visões e necessidades que devem ser analisadas antes da definição do tipo e modelo adequado a usuários que devem aprovar seu uso para o espaço público. Sua aprovação envolve padrões ergonômicos e físicos e sua usabilidade acrescenta aspectos emocionais e perceptivos, de aceitabilidade e representatividade.

"A acessibilidade é um tema que vem sendo discutido cada vez mais pela sociedade" (FERREIRA; BIAZOLI, 2013). Em se tratando do design de louças destinadas a sanitários acessíveis, os aspectos gerais se tornam ainda mais suscetíveis ao erro. É importante frisar que o que determina a acessibilidade de um sanitário não é o desenho diferenciado e 'exótico' de um vaso sanitário, mas a obediência às regras pré-estabelecidas para um projeto correto que represente as necessidades a serem nele inseridas. "Não há meia inclusão ou meia acessibilidade" (FERREIRA; BIAZOLI, 2013). Portanto, adotar um design fora do tradicional para uma bacia sanitária pode melindrar ou causar um estranhamento por parte dos usuários, além de não determinar a acessibilidade pretendida. Esta perspectiva se complica ainda mais ao se instalar este tipo de peça em ambientes públicos para uso coletivo (destinado a grupos com e sem necessidades especiais conjuntamente). $\mathrm{O}$ uso de peças extremamente caracterizadas, atípicas e específicas, com aberturas, fendas e formas visivelmente distintas, destinadas a pessoas com restrições de movimentos, cadeirantes, ou portadores de necessidades especiais, pode causar constrangimentos aos usuários, e principalmente aos que não carecem destas necessidades, como é o caso do uso compartilhado. Este uso comum, coletivo, ocorre em função das normas vigentes, com exigências para os espaços públicos de um sanitário destinado a acessibilidade, recaindo em grande parte 
dos estabelecimentos em um único sanitário de função compartilhada, coletiva e acessível.

Disponibilizar um modelo de vaso sanitário que atenda a especificações e necessidades de acessibilidade é uma tarefa que exige coerência e respeito às normas, e deve ser orientada por regras essenciais constantes na NBR 9050. Estabelecida em referencias acessíveis desde 2004, a norma apresenta, em sua nova versão, atualizada em 2015 (NBR 9050:2015) restrições à instalação desta peça de forma clara. Pela citada norma, no ítem 7.7 - Bacia sanitária - consta: "As bacias e assentos em sanitários acessíveis não pode ter abertura frontal' (ABNT NBR 9050:2015, 2016).

Além desta normatização não estar sendo respeitada, o que se verifica constantemente quando se realizam pesquisas nesta área é a ocorrência da falta de padrão ou total desconhecimento da existência de uma normatização por parte de quem executa a construção de um sanitário público ou comercial.

$\mathrm{Na}$ falta de um órgão específico que fiscalize as normatizações estabelecidas para este grupo de indivíduos em todas as obras, as pessoas com necessidades especiais de mobilidade buscam apoio em alguns sites específicos, que têm se voltado a esclarecer incertezas, discutir e orientar questões de usabilidade e acessibilidade a portadores de necessidades especiais, como o site 'Deficiente Ciente', e o site 'Design Universal'. Neles foram verificados depoimentos e críticas à peça com fenda frontal, denotando reprovação e insatisfação. Foram notadas observações bastante contundentes, como as de Maior (2013) retiradas de um artigo da fisiatra para a revista Revista Nacional de Reabilitação - REAÇÃO, afirmando que: "o vaso sanitário com abertura frontal é um erro, não é normal' (MAIOR, 2013, DEFICIENTE CIENTE, 2016).

Ferreira e Biazoli (2013) alteraram esta visão e interpretação ao declarar que "o vaso sanitário com abertura frontal não é um erro", porém seu "uso em sanitários acessíveis é que constitui um erro". Em seu entender, o erro não está no projeto, fabricação e comercialização do vaso com abertura, mas sim no uso aplicado a sanitários comuns e sem acompanhamento, sendo destinado a ambientes hospitalares e similares, e a pessoas que necessitam de cuidados especiais e auxílio de terceiros, inclusive para realizar higiene íntima (FERREIRA; BIAZOLI, 2013). A peça avaliada nesta pesquisa aplicada de caráter transversal traz em seu apelo de diferenciação e sua proposta de uso, o fato de facilitar a higiene íntima de pessoas com restrições de movimentos. Muito embora tenha sido verificado que a higiene pretendida ocorre em ambiente doméstico e hospitalar, e não em ambiente público e comercial. No entanto, desde 2012, segundo divulgado pelo site Design Universal (2013), e pelo site Deficiente ciente (2014), este tipo de bacia tem gerado polêmica e divergências por parte de usuários, e seu uso foi limitado a locais específicos da área hospitalar e de cuidados especiais, com acompanhantes. A decisão por esta medida ocorreu por conta de acidentes com este tipo de abertura, que não acomoda com segurança o usuário. $A$ liminar foi publicada pelo MPF (2013), por meio da Procuradoria Geral da República e acompanha uma instrução de estudo jurídico-científico (FERREIRA; BIAZOLI, 2013), gerado após o laudo. No ato foi solicitada a reformulação das normas da ABNT neste sentido por meio da NBR 9050, tanto para uso daqueles indivíduos que apresentam restrições de movimento como para os que não as apresentam. A peça avaliada apresenta uma série de características desfavoráveis e inadequadas e recebeu críticas constantes por parte dos usuários, corroboradas pela médica fisiatra e secretária Nacional de Promoção dos Direitos da Pessoa com Deficiência, Isabel Maior (2013). 
Outro aspecto verificado na abordagem dos sites foi o completo desconhecimento da função da abertura frontal, por parte da maioria. Algumas afirmações surpreenderam, com a conclusão de que a abertura se justificaria como encaixe da cadeira de rodas de cadeirantes, entre outras possíveis suposições. $O$ enfoque revela que o produto não é entendido pelo design proposto. $O$ projeto não descreve a função de uso pela imagem.

O presente artigo demonstra, sob o ponto de vista ergonômico, uma análise da usabilidade do modelo de bacia sanitária com abertura frontal, em sanitários de uso coletivo. Ao longo do estudo pôde ser verificado que esta peça não atende com qualidade às necessidades essenciais físicas, emocionais e à expectativa por salubridade que os usuários esperam. Acarreta problemas de respingos, inadequação, desconforto físico e emocional, gera constrangimento e falhas de salubridade.

\section{FUNDAMENTAÇÃO TEÓRICA}

\subsection{Determinações Para Restrição e Utilização da Peça Com Abertura Frontal}

O vaso sanitário, objeto da análise, é disponibilizado comumente em locais públicos e comerciais, a todos os tipos de usuários, com indicação de especificidade para portadores de necessidades especiais e idosos. $O$ modelo selecionado para 0 estudo possui uma grande abertura frontal e encontra-se disponibilizado pelo mercado há cerca de 5 anos. No entanto, contraria a atual norma brasileira da ABNT NBR 9050:2015, que determina, entre outros, o tipo de louça sanitária e as especificações para instalação e uso. "Se o vaso instalado não atende às especificações, e apresenta uma abertura frontal, tal banheiro não é acessível" (FERREIRA; BIAZOLI, 2013). As "regras de acessibilidade foram editadas com um único propósito: garantir a plena inclusão das pessoas com deficiência, remetendo ao conceito de desenho universal" e ao princípio da igualdade. A fisiatra Isabel Maior (Secretária Nacional de Promoção dos Direitos da Pessoa com Deficiência), no artigo supracitado: ninguém conhecia a razão do desenho e da sua utilidade. A origem de tal design pode ser a necessidade hospitalar de outra pessoa auxiliar a higiene do paciente. Considerando essa utilidade, o ambiente é a internação e nunca shoppings, hotéis, aeroportos, terminais rodoviários e mesmo restaurantes. Arremata a citada médica que a bacia sanitária de abertura frontal revela a confusão que se faz entre pessoas com deficiência e doentes e ainda é tão forte que levou os vasos sanitários hospitalares para os espaços públicos. Desta forma, revela a falsa impressão que os vasos sanitários estão adaptados de maneira correta.

Figura 1: Modelo analisado - bacia / vaso com abertura frontal grande
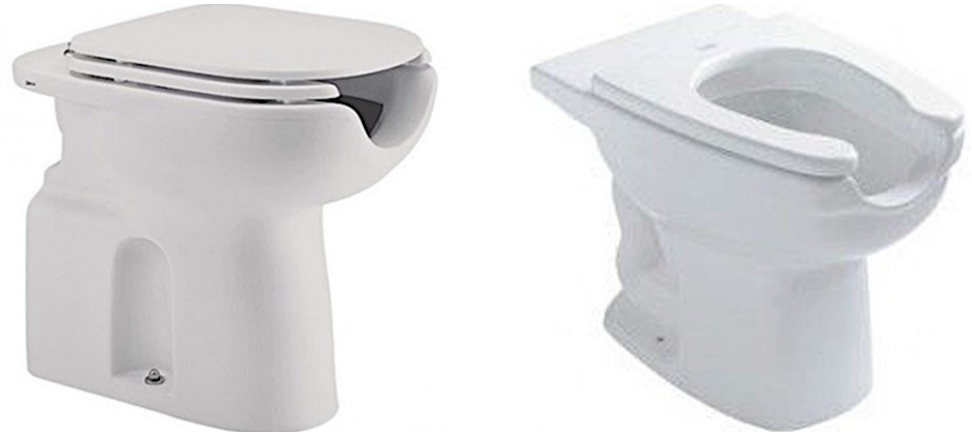

Fonte: www.deficientenobanheiro.wordpress.com/, 2013. 
A consequência gerada pela instalação de vaso sanitário com abertura frontal em locais públicos ou acessíveis ao público tem causado reclamações de usuários cadeirantes e também de pessoas idosas. Reclamam do desconforto e situação desagradável da urina escorrer para fora do vaso, causando odores e a falta de higiene com o chão molhado, que é tudo o que uma pessoa com deficiência não deseja. Ademais, não é funcional, mas sim, arriscado, pois as pernas podem cair dentro da abertura provocando problemas como queda, lesões, torções, etc. Com efeito. Não é cabível a instalação de uma bacia sanitária de natureza hospitalar em banheiros públicos, ou outros ambientes, para justificar a acessibilidade do mesmo. Em outras palavras, não é o vaso sanitário que caracteriza um banheiro acessível, e sim todo o conjunto de adaptações que são realizadas no espaço. $O$ assunto foi tema de artigo em uma revista especializada em inclusão e acessibilidade para pessoas com deficiência, oportunidade em que a médica fisiatra Izabel de Loureiro Maior, esclareceu que o vaso sanitário com abertura frontal é um erro, não é norma. Relatou também, em seu artigo, que a venda dessas peças continua a todo vapor e que as fábricas de louças sanitárias devem ser instruídas a separar a linha hospitalar da linha de produtos para pessoas com deficiência; os arquitetos e proprietários de estabelecimentos precisam ser obrigados a seguir o constante na norma técnica da ABNT, NBR9050/2004, na qual não consta a bacia sanitária com fenda frontal.

\subsection{Design diferenciado não pressupõe acessibilidade e adequação}

Uma pesquisa envolvendo testes foi realizada por professores da Faculdade de Arquitetura, Urbanismo e Design da Universidade Federal de Uberlândia (UFU) que atestaram que a bacia com abertura frontal oferece risco. $O$ teste foi solicitado a pedido do Ministério Público Federal (MPF, 2013). Tecnicamente e ergonomicamente, a alegação se embasa no fato de que essa "bacia sanitária causa insegurança e risco para a integridade física dos usuários, havendo inclusive uma petição pública contra sua instalação em locais de uso coletivo". A alegação se fortalece embasada pelo fato de que a peça não oferece essencialmente "o apoio total das pernas, causando acidentes e torções" (MPF, 2013). Na pesquisa da UFU foi constatada a falta de segurança para os usuários que utilizam a bacia desacompanhados. O grupo verificou vários portadores de necessidades especiais, além de idosos e crianças, estabelecendo que os riscos ocorrem em todos usuários desacompanhados, com quaisquer restrições de movimento. Baseado neste teste e no laudo final produzido a partir dele, o MPF emitiu um parecer solicitando à ABNT a adequação da norma NBR, sob alegação de que a informação deveria ser adotada e efetuadas as correções:

\footnotetext{
"Até há bem pouco tempo, essa informação não era de domínio público. É possível que, ainda hoje, encontremos profissionais da área acreditando que a bacia com abertura frontal seja o modelo mais adequado a todas as pessoas com deficiência, indistintamente. Por isso, oficiamos ao Conselho Federal de Engenharia e Agronomia (CONFEA) e ao Conselho de Arquitetura e Urbanismo de Minas Gerais (CAU/MG) solicitando sua colaboração no sentido de difundir e esclarecer o assunto junto aos profissionais de engenharia e arquitetura". A própria Associação Brasileira de Normas Técnicas (ABNT) comprometeu-se a editar norma técnica sobre bacias sanitárias para pessoas com deficiência que contemple a vedação da bacia com abertura frontal em sanitários públicos de uso coletivo. A medida irá suprir duas lacunas atualmente existentes: não existe norma brasileira específica para bacias sanitárias e a norma que trata de
} 
acessibilidade em banheiros não contempla o modelo com abertura frontal. " (Procurador MACEDO) (PGRMG/MPF, 2013).

Além da informação dirigida ao CONFEA e ao CAU, o MPF (2013) deliberou pela substituição e troca destas peças nos órgãos e instituições públicas federais: "nos quais for detectada a existência do modelo inadequado ao uso de pessoas com deficiência" e "Trata-se de medida de segurança e não só de mero conforto" (MACEDO, PGRMG/MPF, 2013). Uma medida complementar a esta, definiu que os fabricantes devem informar devidamente os consumidores, para evitar a indução de erro na compra deste produto.

A medida por si só explicita que a peça não se adequa a pessoas com deficiências, portanto, se adequa ainda menos a pessoas sem qualquer restrição ou deficiência. Os únicos locais públicos com permissão para a utilização e instalação deste tipo de bacia após o parecer do MPF são os hospitais, clínicas e residências, "onde o usuário tem a companhia de uma pessoa para auxiliá-lo na higienização" (MPF, 2013). Pelos laudos e testes, a recomendação de uso desta peça ficou restrita ao acompanhamento obrigatório do usuário. Ficou igualmente restrita ao ambiente hospitalar, clínicas ou domiciliar com cuidador. Isso exclui sua instalação e utilização em shoppings, escolas e agências bancárias. Entretanto, até o momento, a peça é comumente encontrada em vários locais públicos. Destaca-se o sanitário do Departamento Jurídico da UNESP, possui esta bacia sanitária; não foi exigida ou efetuada a troca. Neste local foi realizada uma parte das entrevistas dirigidas.

Pode-se constatar que decorridos 3 anos desde o parecer do MPF, uma nova NBR 9050, atualizada no ano 2015, e definiu que a bacia com abertura frontal não é adequada a sanitários de acessibilidade, sanitários coletivos e espaços públicos comerciais em geral. Percebe-se um desconhecimento da NBR RECENTE pois esta orientação ainda não foi totalmente acolhida. Locais públicos ainda não foram instados e a peça continua sendo comercializada e instalada em sanitários coletivos. Estes ambientes protelarão as trocas devido a custos e ao inconveniente de se submeterem a reformas.

\footnotetext{
"Não há necessidade de comprar um vaso de determinado modelo. Qualquer vaso que com a tampa fique com 46 centímetros de altura está correto. Se o vaso é mais baixo, vale fazer uma base de concreto, o "sóculo" para elevar" (FROTA, 2010). "Devemos tomar cuidado com a base do vaso, pois malfeita impede a aproximação da cadeira de rodas ou alguém pode bater o dedinho do pé. E no caso do segundo vaso, que é mais baixo, tem também a solução de comprar um tampo com 5 centímetros de altura, porém esse tampo não está na Norma de Acessibilidade, alguns arquitetos falam que ele é instável, e se não estiver bem preso a pessoa pode escorregar. E devido ao preço, andam roubando este tampo" (FROTA, 2010).
}

Diversos modelos de peças sanitárias foram desenvolvidos desde o final da última década, em decorrência da exigência de espaços, aparelhos e equipamentos específicos para deficientes físicos, ou portadores de deficiências físicas, ou melhor denominados portadores de necessidades especiais. Sendo assim, se há escape de líquido pela abertura frontal (grande), e, se a função da borda no design do vaso sanitário é justamente bloquear o retorno de urina e reduzir os respingos, qual a função da abertura nesta peça? Há críticas sobre outras falhas no projeto de bacias acessíveis propostas, como a altura determinada, esta sim, essencial e obrigatória, para a 
instalação de um vaso sanitário em banheiro acessível. A altura inadequada do vaso sanitário e ausência de barras de apoio em locais essenciais são elementos de maior importância dentro do contexto, conforme verificado em estudos com especificidades relativas ao tema (THOBER; CREUTZBERG; VIEGAS, 2005).

Normas da ABNT estabelecem e padronizam a altura necessária para bacias sanitárias. Inicialmente a norma de 2004 (NBR 9050:2004) definiu padrões de altura e o espaço de circulação para cada louça a ser instalada e ambientes de acessibilidade. Posteriormente, a atualização da norma, constante no item 7.3.1.3 - NBR 9050:2015, Pelo item 7.7.2.1 - Altura da bacia - completa que "bacias e assentos acessíveis não podem ter abertura frontal e devem estar a uma altura entre 0,43 e 0,45 cm do piso acabado, medidas da borda superior sem o assento".

Figura 3: Determinação de alturas para bacia e assento em sanitários de acessibilidade

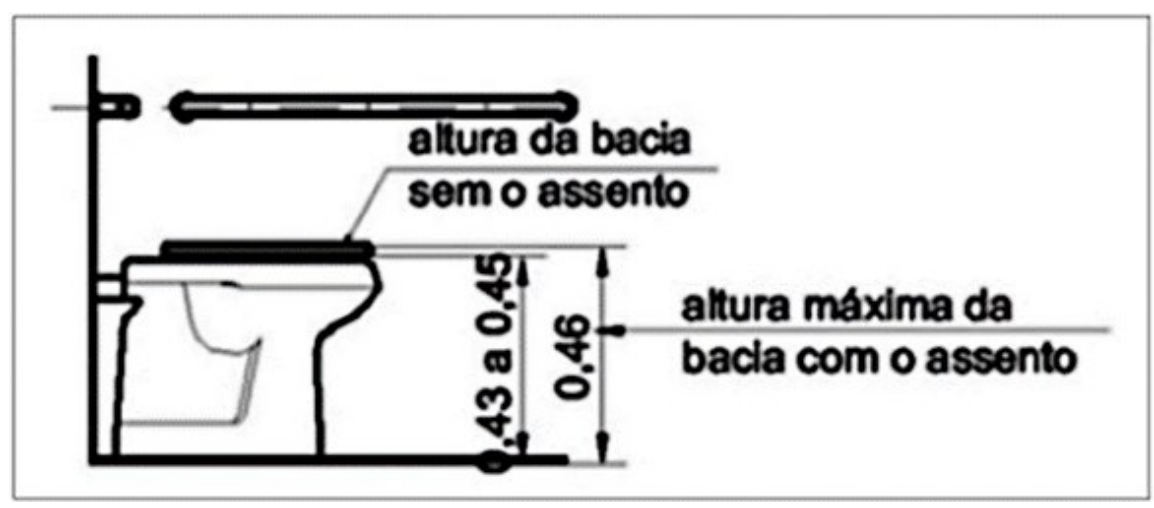

Fonte: https://thaisfrota.wordpress.com/2010/05/18/bacia-sanitaria/, 2015.

Pelo item 7.7.2.1 - Altura da bacia - completa que "bacias e assentos acessíveis não podem ter abertura frontal e devem estar a uma altura entre 0,43 e $0,45 \mathrm{~cm}$ do piso acabado, medidas da borda superior sem o assento" (ABNT NBR 9050:2015, 2016).

\section{PROCEDIMENTO METODOLÓGICO}

O método utilizado neste estudo ergonômico sobre adequação entre interface e usuário, tem caráter exploratório descritivo dedutivo. A pesquisa para a coleta de dados foi realizada em locais públicos e se iniciou com 2 entrevistas dirigidas, numa amostragem composta por 10 indivíduos de diversas faixas etárias, contemplando os dois gêneros. A $1^{\mathrm{a}}$ entrevista foi cumprida no departamento de uma instituição pública, na cidade de Bauru (SP), que apresenta um sanitário coletivo com bacia de abertura frontal. Este sanitário é utilizado por todas as pessoas que trabalham no local, e outras que utilizam os serviços do Dept $^{\circ}$ esporadicamente. O sanitário é unissex e de uso coletivo e acessível. A única bacia disponibilizada corresponde ao modelo pesquisado, de abertura frontal. Quatro usuários frequentes do Dept ${ }^{\circ}$ foram questionados com relação a cinco aspectos: satisfação, adequação, design, desconforto físico e respingos/ salubridade. A $2^{\mathrm{a}}$ entrevista dirigida foi realizada no ambiente público de um shopping center, em um restaurante de movimento intenso. Foram questionadas seis pessoas, apenas do sexo feminino, sobre as mesmas especificidades e questões.

A consulta às normas da ABNT NBR 9050:2004 e NBR 9050:2015 foram determinantes no aspecto de padronização e determinação quanto ao uso e local. Após 
a fase de análise da bibliografia foi elaborado um questionário on-line, pela plataforma Google Forms, com foco em obter respostas concretas e determinar o nível de adequação, satisfação quanto à ergonomia, design e salubridade e como é vista a usabilidade deste tipo de peça, nos aspectos físicos, emocionais e perceptivos.

O universo de indivíduos entrevistados por meio do questionário on-line alcançou um total de 93 usuários de ambos os gêneros, entre 15 e 80 anos, que se utilizaram de sanitários coletivos com a referida bacia analisada, com abertura frontal. Dentre estes, encontram-se idosos, jovens, indivíduos com restrições de movimento, cadeirantes e indivíduos sem quaisquer restrições.

O questionário priorizou inicialmente a separação dos grupos satisfeitos e grupos insatisfeitos com o uso da peça. Após esta separação, procedeu-se à análise da interface, em relação ao usuário insatisfeito, esmiuçando todos os aspectos referentes ao grupo que julgou o produto inadequado.

\section{RESULTADOS}

O perfil das respostas indicadas a seguir, obtidas a partir do formulário elaborado, apresenta índices que corroboram a inadequação e insatisfação dos usuários com as propostas de ergonomia, design, usabilidade, adequação e função da bacia sanitária com abertura frontal. Destaque-se aqui a questão de espaço de tempo de uso desta peça, que se encontra disponibilizada pelo mercado há mais de 5 anos, mantendo-se boa parte dos usuários na opção insatisfeitos. Dada esta ressalva prosseguem-se os dados numéricos e percentuais. A amostragem dos dados por gênero foi composta por $71 \%$ de respondentes do gênero feminino e 29 do gênero masculino, divididos em diversas faixas etárias de acordo com a Figura 4, a seguir:

- $71 \%$ respondentes do gênero feminino

- $29 \%$ respondentes do gênero masculino

\section{Figura 4: Caracterização da Amostra segundo faixa etária e gênero}

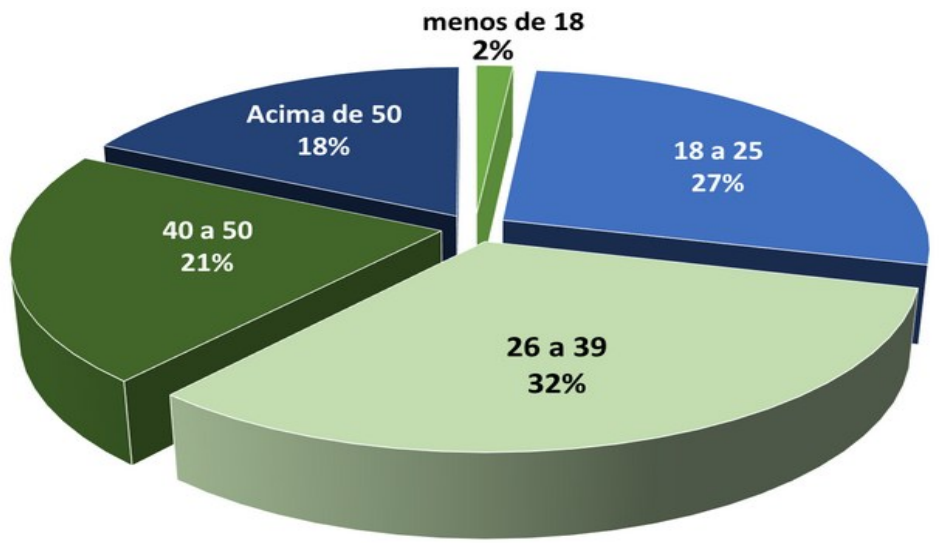

Fonte: Elaborado pelo Autor, 2016.

A relação de insatisfeitos alcançou $65 \%$ dentre todos os respondentes. Homens e mulheres selecionaram inadequações no produto. Desta maneira, os resultados trazem a composição das questões relativas aos sujeitos que seguiram a pesquisa online na opção 'insatisfeito' com o uso da peça. Inicialmente foi abordado o nível de insatisfação geral dos usuários, atribuindo-se um conceito para a insatisfação com a usabilidade da interface, com graus relacionadas em escala de 0 (satisfeito) a 5 
(insatisfeito). A concentração de insatisfeitos foi predominante e se tornou ainda maior, quanto maior a idade dos respondentes. As respondentes do gênero feminino se mostram ainda mais insatisfeitas a partir dos 40 anos; os do gênero masculino a partir de 26 anos indicam cedo sua insatisfação, numa proporção de cerca de $70 \%$ do total de respondentes.

Figura 5: $\mathrm{N}^{\circ}$ de usuários insatisfeitos quanto á dificuldade de uso com relação a aspectos físicos e emocionais

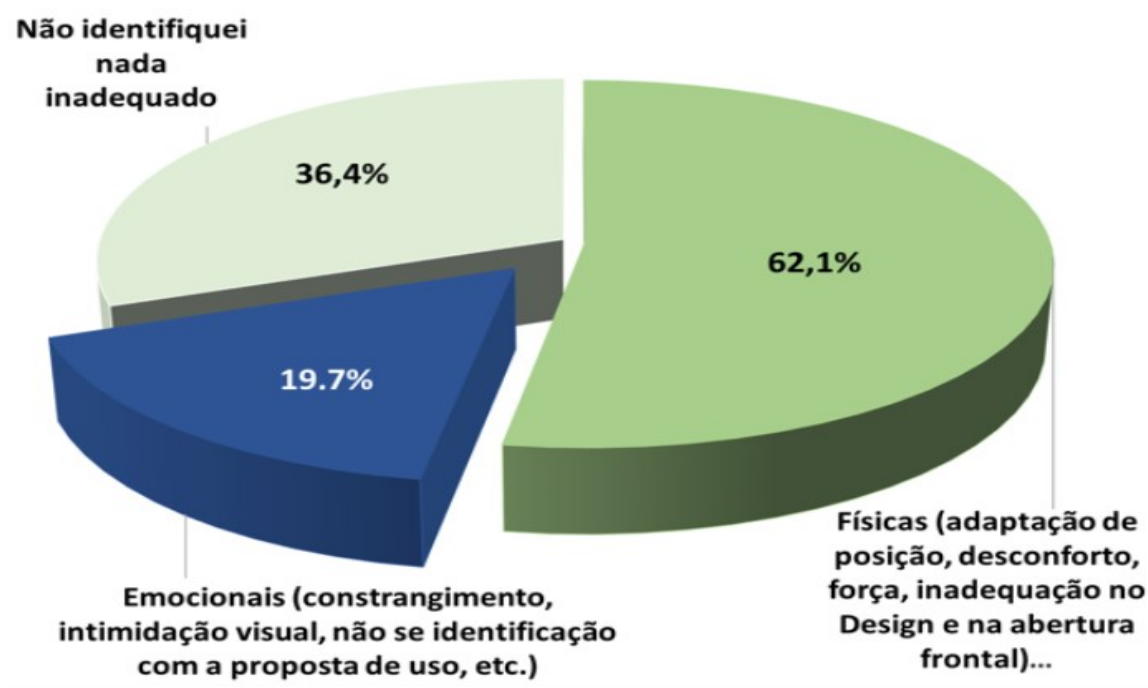

Fonte: Elaborado pelos autores, 2016.

O nível de insatisfação geral dos usuários envolve aspectos físicos e emocionais, e neste viés de análise os respondentes puderam manifestar ambas as percepções, físicas e emocionais ilustradas na Figura 5, onde $62,1 \%$ relatam dificuldade física e inadequação na utilização. Cerca de $20 \%$ destes indicam constrangimento emocional.

Figura 6: $\mathbf{N}^{\circ}$ de usuários insatisfeitos nos aspectos da percepção de conforto

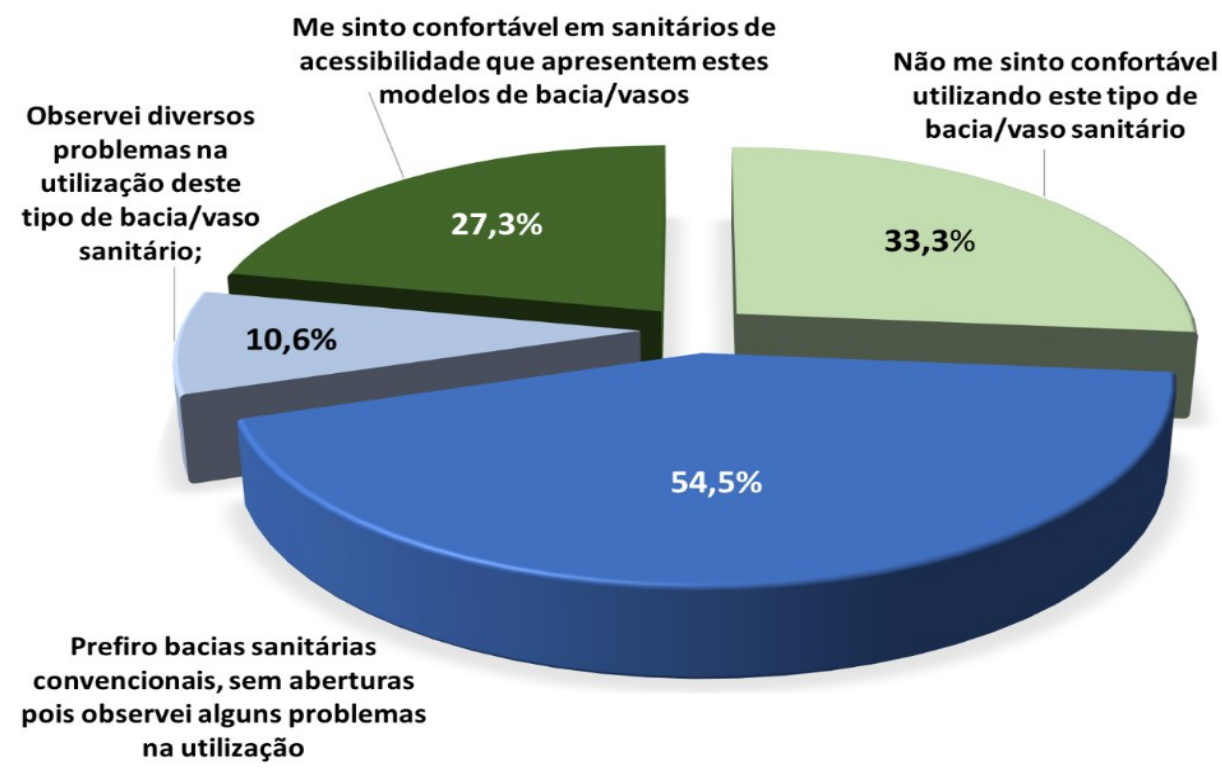

Fonte: Elaborado pelos autores, 2016. 
A grande maioria dos usuários se sente insatisfeita com a proposta continuada de uso da peça. Pela Figura 6 , somente $27,3 \%$ dos usuários entende a bacia como adequada, ou seja, perto de 1/4 do total de sujeitos questionados. Enquanto cerca de $55 \%$ preferem as bacias convencionais. A Figura 7 apresenta indicadores diversos de inadequação e insatisfação.

\section{Figura 7: Indicadores dos aspectos negativos mais frequentemente observados em \%}

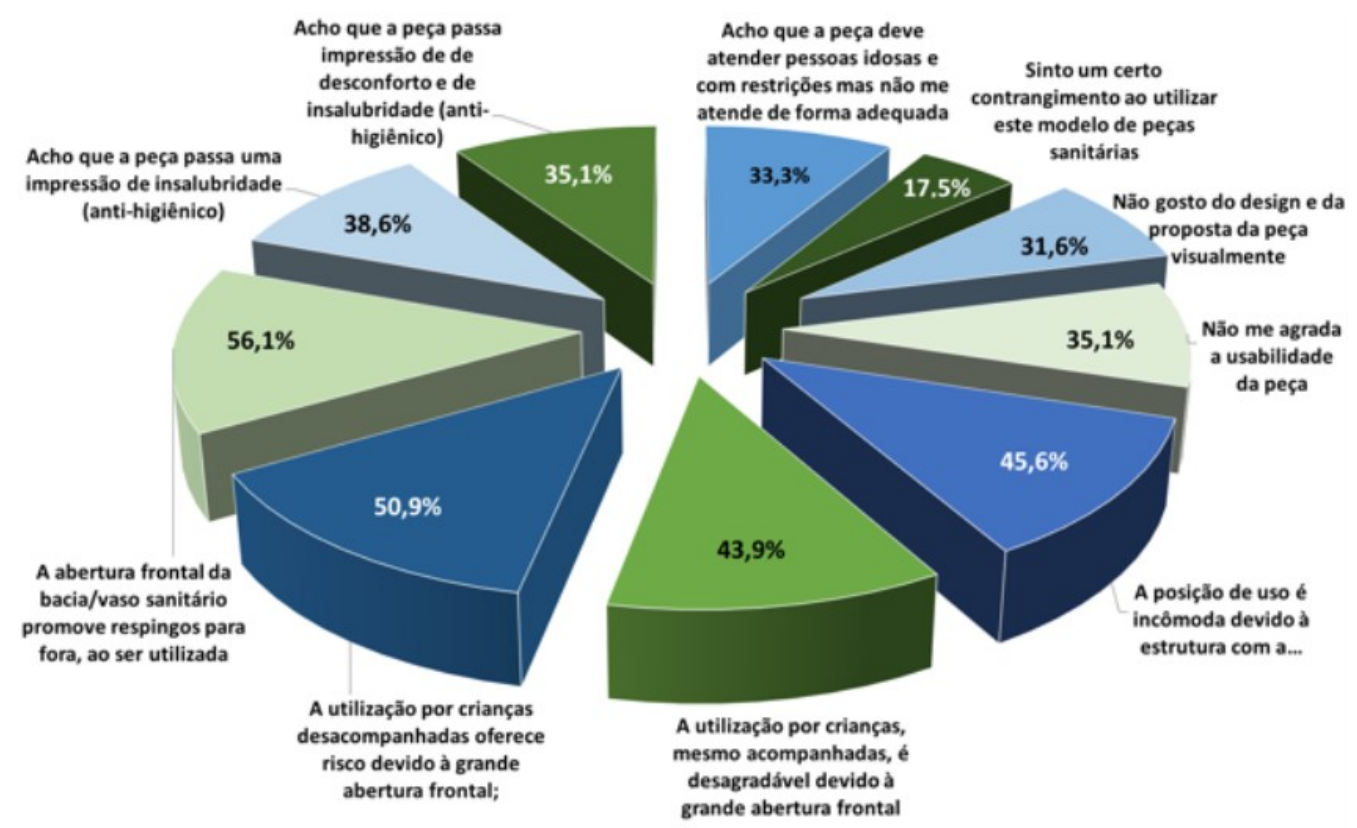

Fonte: Elaborado pelos autores, 2016.

Entre os aspectos negativos mais destacados, $54,1 \%$ dos usuários relatam os respingos pela fenda da abertura frontal. Isso consequentemente recai em níveis de insalubridade. Os respondentes indicaram que o desconforto e a inadequação postural são o pior aspecto, $45,6 \%$, seguido por cerca de $44 \%$ dos usuários que acreditam que esta peça é totalmente inadequada para o uso de crianças, estejam elas acompanhadas ou não. Quanto à utilização deste modelo de bacia sanitária por crianças acompanhadas ou desacompanhadas, $50 \%$ dos respondentes acreditam que esta peça sanitária é inadequada, também para crianças com restrições de mobilidade, além de serem inadequadas para crianças sem quaisquer restrições, acompanhadas por adultos ou não. Ao questionar ambos os grupos, indivíduos sem qualquer restrição somados aos que apresentam restrição de movimento, quanto à insatisfação em aspectos físicos, cerca de $65 \%$ dos usuários se sentem insatisfeitos com o produto. Quanto à percepção de adequação às expectativas de representação da função, e a percepção de conforto, em que cerca de 33, $3 \%$ dos indivíduos questionados não se sentem confortáveis ao utilizar a peça. Um total de cerca de $55 \%$ prefere utilizar as bacias convencionais, sem aberturas.

A pesquisa igualmente buscou identificar a dificuldade de utilização nas primeiras vezes em que o respondente fez uso desta peça. O grupo de pessoas com necessidades especiais e restrição de movimentos gerou $90 \%$ de usuários insatisfeitos com a peça ao início de um processo de aprendizagem de utilização da mesma. Ao longo do tempo de uso esta proporção reduziu para cerca de $53 \%$ dos usuários 
insatisfeitos, o que configura índices bastante insatisfatórios ao sujeito ao qual o produto se destina. Com relação aos cadeirantes, idosos e pessoas com restrição de movimentos que foram questionados, os dados são desanimadores, $90 \%$ encontraram dificuldades iniciais. Os resultados são adversos ao que propõe a ação de marketing do produto, destinados a pessoas idosas e desabilitadas em seus movimentos, o que não procede.

\section{DISCUSSÃO E CONSIDERAÇÕES FINAIS}

A situação de risco que a peça oferece foi qualificada por acidente relatado, que gerou decisão de restrição de uso sem acompanhamento e em locais públicos comuns, determinada pelo MPF, após laudo técnico científico realizado por doutores em universidade da área de saúde. Desrespeitando todas as evidências, a peça continua sendo utilizada e comercializada. É apresentada aos clientes como uma solução "representativa" de um produto com visual de "acessibilidade". Desta forma, os estabelecimentos públicos e comerciais recorrem à sua instalação para atender as normas exigidas para a liberação e funcionamento. Falham neste processo os fabricantes, os vendedores e os prestadores de serviço que desconhecem e desrespeitam as normas, utilizam e sugerem o uso de uma peça claramente impedida por determinação judicial (restrita a hospitais e instituições específicas de cuidados a desabilitados e idosos). Uma característica determinante percebida nas abordagens diretas é a de que nenhum dos entrevistados tinha conhecimento da função da abertura frontal ou da limitação de uso desta bacia, imputada pela decisão do MPF (2013), permitindo o uso apenas com acompanhamento, e em ambientes hospitalares e específicos para cuidados especiais. Registre-se como exceção, no processo de respostas, o retorno por e-mail de um respondente, que muito auxiliou a pesquisa com a informação atualizada da norma da ABNT atualizada em 2015.

O desconhecimento e a insatisfação dos usuários com relação à adequação das bacias sanitárias com abertura, e sua usabilidade, ficou evidenciado tanto em grupos específicos (restrição de movimentos e idosos), como no grupo de usuários em geral. $A$ pesquisa aplicada foi essencial e importante no sentido de constatar o mau design. Um projeto que não atende de fato a nenhum usuário com níveis de usabilidade considerados satisfatórios com relação à adequação da peça, como mostram os resultados. Isto se torna mais grave ao se comprovar que a proposta se equivoca em sua essência de acessibilidade. Incorre em erro da relação interface-usuário sob diversos aspectos que deveriam ter sido amplamente analisados antes de lançar o produto no mercado sob o rótulo de proposta e solução de acessibilidade. De fato, a bacia sanitária força um posicionamento incorreto, respinga urina e líquido de dentro da bacia para fora; coloca em risco a segurança do usuário, especialmente idosos e crianças; não fornece apoio adequado para a parte posterior das coxas e constrange sujeitos desnecessariamente.

Por fim, os resultados indicaram que o design é o indutor das falhas, e que existe um erro na premissa de sua concepção somado ao local e forma incorreta de sua utilização, é importante ressaltar que apenas um novo e adequado projeto com um design correto poderá se sobrepor ao equívoco. É necessário conceber um produto que atenda a todas as especificações e expectativas de necessidades, e com respeito aos usuários em questões físicas e emocionais para suceder à utilização desta peça inadequada. Num último viés conclusivo, a análise demonstrou que peças com um 
visual tido como 'agressivo' ou 'exótico', num contexto de higiene, e aplicadas a soluções de sanitários de uso coletivo, tiram o usuário de sua zona de conforto físico, familiaridade, percepção e satisfação emocional, e são repudiadas pelos indivíduos em geral.

\section{AGRADECIMENTOS}

Agradeço à FAPESP - Fundação de Apoio à Pesquisa do Estado de São Paulo, pelo apoio que possibilitou a realização desta pesquisa por meio dos Processos de $\mathrm{N}^{\circ} \mathrm{s}$ 2014/19854-2 e 2016/11169-4.

\section{REFERÊNCIAS BIBLIOGRÁFICAS}

ABNT. Norma Brasileira ABNT NBR 9050:2004. 31.05.2004. Disponível em: <http://www.pessoacomdeficiencia.gov.br/app/sites/default/files/arquivos/\%5Bfield_generico_im agens-filefield-description\%5D_24.pdf>. Acesso em 10 jun.2016.

Norma Brasileira ABNT NBR 9050:2015. 11/09/2015. Disponível em: <https://www.abntcatalogo.com.br/norma.aspx?ID=344730>. Acesso em 20 jun. 2016.

DESENHO UNIVERSAL. Desenho Universal - Habitação de Interesse Social. MPF Ministério Público Federal - Procuradoria da República em Minas Gerais. Disponível em: $<$ http://www.prmg.mpf.mp.br/>. Acesso em 27 jun.2016.

INSTITUTO BRASILEIRO DOS DIREITOS DA PESSOA C DEFICIÊNCIA (IBDD). Disponível em: $<$ http://www.ibdd.org.br/>. Acesso em 12 jun.2016.

DIÁRIO DO LEGISLATIVO. Projeto de Lei No 4.651/2013 - Dispõe sobre requisitos de acessibilidade de bacias sanitárias em espaços públicos e dá outras providências. Artigo $3^{\circ}$ Inciso II. In: Informativo Online - MPMG, 01.11.2013. Matérias Legislativas em Tramitação (www.almg.gov.br) Vol.13. N38. Disponível em: <http://ws.mpmg.mp.br/biblio/informa/011119224.htm>. Acesso em: 27 jun. 2016.

FERREIRA, L. A. M.; BIAZOLI, J. A. O Vaso Sanitário e as pessoas com deficiência. MPRGS. Ministério Público do Rio Grande do Sul. Disponível em: $<$ https://www.mprs.mp.br/areas/infancia/arquivos/vaso_sanitario_e_pessoas_com_deficiencia..

MACEDO, L. Procuradoria da República em Minas Gerais - PGRMG. Disponível em: $<$ http://www.prmg.mpf.mp.br/imprensa/noticias/direitos-do-cidadao/bacia-sanitaria-comabertura-frontal-nao-deve-ser-utilizada-em-banheiros-de-uso-coletivo-para-pessoas-comdeficiencia>. Acesso em 27 jun.2016.

MAIOR, I. M. M. L. Vaso sanitário com abertura frontal é um erro, não é normal! - Revista Nacional de Reabilitação - REAÇÃO. São Paulo: ano XVI, n. 92, maio/junho de 2013 - págs. 100-101.

Deficiente Ciente (Site). Disponível em: <http://www.deficienteciente.com.br/vasosanitario-com-abertura-frontal-e-um-erro-nao-e-norma.html>. Acesso em 19 jun.2016.

THOBER, E., CREUTZBERG, M., VIEGAS, K. Nível de dependência de idosos e cuidados no âmbito domiciliar. Revista Brasileira de Enfermagem - REBEN. Jul-AGO 2005, v.58, N. 4, p. 438-43. Disponível em: <http:/www.scielo.br/pdf/reben/v58n4/a11v58n4>. Acesso em 02 jun. 2016. 